\title{
Ebselen-containing Oral Capsule SPI-1005
}

National Cancer Institute

\section{Source}

National Cancer Institute. Ebselen-containing Oral Capsule SPI-1005. NCI Thesaurus.

Code C98398.

An oral capsule containing a proprietary formulation of the organoselenium compound ebselen, with potential anti-oxidant, anti-inflammatory and cytoprotective activity. Upon oral administration of SPI-1005, this agent mimics the activity of glutathione peroxidase (GPx) and can utilize glutathione to reduce other unstable molecules, thus preventing the formation of reactive oxygen species (ROS) and reducing oxidative stress on the cell. In the cochlea, this agent may prevent drug-induced injury to the auditory hair cells thereby preventing hearing loss. GPx is the main antioxidant enzyme in the cochlea and protects the inner ear from loud sounds and biochemical damage. In addition, ebselen is able to inhibit the activity of many enzymes involved in inflammation. 